\title{
Long-term recovery of visual reaction time after closed head injury ${ }^{1}$
}

\author{
A. H. VA N Z M R R N A D B. G. DEELMA N \\ From the Neuropsychology Department, State University, Groningen, The Netherlands
}

SUMMARY A follow-up study covering two years after a closed head injury was carried out on a group of 57 young males. Their reaction time was tested on both a simple and a four choice visual reaction task. The group was divided into three subgroups according to length of unconsciousness after the injury. Reaction time discriminated between subgroups, and a highly significant improvement during follow-up was shown. Choice reaction time discriminated better and continued to do so throughout the whole period of follow-up. Some relations of reaction time with clinical variables and outcome are discussed. The choice reaction in particular seems to have some value for monitoring recovery and predicting final outcome.

After cerebral concussion patients may show a slowness of thought which nowadays is usually described as a slowing down of information processing. This phenomenon should not be confused with the old clinical concept of "bradyphrenia," a state observed in subjects who have sustained very severe head injuries only. As Gronwall and Wrightson (1974) have shown, the slowing down of information processing can be demonstrated even in patients with mild concussions who have a good prognosis. They found a slowing down in a paced serial addition task during approximately the first five weeks after the injury. There are a few reports about prolonged reaction time after head injury (Norrman and Svahn, 1961; Miller, 1970; Klensch, 1973; Gronwall and Sampson, 1974). In most of these studies choice reaction time seemed a more sensitive test than simple reaction time, although this was not confirmed by Klensch (1973).

The above investigations were carried out on small groups of patients who were tested only once. For that reason we felt the need for a longitudinal investigation on a somewhat larger group. The main aim of our study was to construct recovery curves for simple and choice reaction times over a period of two years after the injury, using severity of injury as an independent variable.

\footnotetext{
${ }^{1}$ This paper was presented at the International Neuropsychology Society European Conference, Oxford, August 1977.

Address for reprint requests: Dr A. H. van Zomeren, Neurological Department, Academic Hospital, Groningen, Netherlands.

Accepted 15 December 1977
}

Moreover, we were interested in the relations of reaction time with the original clinical state of the patients, and with their final outcome.

\section{Method}

SCHEDULE OF FOLLOW-UP

As it is a common clinical opinion that posttraumatic recovery may continue for as long as two years, it was decided to test patients six times in this period. The interval between tests increased regularly, as we expected to find the greatest changes in performance in the beginning of the recovery process. In fact, testing was planned at five weeks, 10 weeks, and five months after trauma, and from then on in the middle of each successive half year.

\section{SUBJECTS}

The sample reported on consisted of male patients in the age range from 16 to 39 years, and represented most of our total head injury population. This homogeneous group was divided into three subgroups according to the severity of the injury. Length of unconsciousness after the accident was used as an index of severity. Disturbance of consciousness is quantified in our department using a scoring system developed by the Neurosurgical Department in Glasgow (Teasdale and Jennett, 1974). This system enables the neurologist to give the patient an objective EMV score ranging from 3 to 15 , covering eye opening $(\mathrm{E})$ and motor response (M) on painful stimulation, and verbal 
performance (V). It is regarded as an adequate way to define "coma" in a patient after head injury, using an EMV score of 8 or less as a criterion. Table 1 shows the number of subjects in each subgroup. Patients in these three groups will be referred to occasionally as mildly, moderately, or severely injured.

Table 1 Number of subjects and mean age in subgroups with different length of unconsciousness

\begin{tabular}{|c|c|c|c|}
\hline Group & Number & $\begin{array}{l}\text { Mean age } \\
(y r)\end{array}$ & Length of unconciousness \\
\hline $\begin{array}{l}\text { Coma } 3 \text { (severe) } \\
\text { Coma } 2 \text { (moderate) } \\
\text { Coma } 1 \text { (mild) }\end{array}$ & $\begin{array}{l}12 \\
18 \\
27\end{array}$ & $\begin{array}{l}23.4 \\
19.7 \\
22.8\end{array}$ & $\begin{array}{l}\text { over one week } \\
\text { one hour-seven days } \\
\text { less than } 60 \text { minutes }\end{array}$ \\
\hline
\end{tabular}

As post-traumatic amnesia is another frequently used index of severity, a survey of its distribution in the present sample is given. All patients in the severe group showed post-traumatic amnesia for four weeks or longer, which makes them "very severe" head injuries according to the classification proposed by Russell and Smith (1961). In the mild group, none of the patients had a posttraumatic amnesia exceeding one week's duration. The duration of post-traumatic amnesia was defined as the interval between the injury and the time taken to attain continuous hour-to-hour and day-to-day memory. Post-traumatic amnesia was assessed daily by the neurologist during the clinical examination. Subjects with motor or sensory deficits that could have hindered performance were excluded from the study. The presence of such deficits was assessed by clinical neurological examination, while, in addition, for the motor function a score in the normal range on a fingertapping test was required.

Although we planned to test each subject six times, only the mild injury group could be tested completely at five weeks since some patients in the other groups were still in a confused state or unconscious at that time. The severe group was not completely fit to be tested at 10 weeks, and its recovery curve, therefore, begins at the five months test.

\section{PROCEDURE}

The apparatus consisted of a panel with a vertical row of four white lights. On both sides of each light there were black push-buttons with the same diameter $(24 \mathrm{~mm})$ as the lights. Parts of this panel could be blocked out so that only the required lights and buttons remained visible. That is,

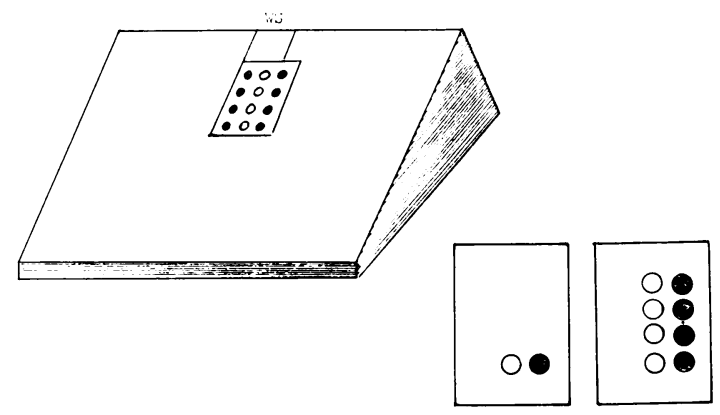

Fig. 1 Apparatus used for recording reaction times. For left handers the metal masks were placed in mirror image. In the four choice panel, the small dot indicates the resting point for the index finger. $W S=$ buzzer for warning signal.

for a right handed subject only the buttons on the right side of the lights would be visible (Fig. 1). In the simple reaction, subjects would see the bottom light and button only. Patients were instructed to push the button next to the presented stimulus as quickly as possible, using their index finger. In the choice reaction, the index finger was held at a resting point situated between the second and third button until a signal was presented. The preferred hand was used, unless this was impossible because of a fracture of the arm (two subjects), or in one case because of hemiparesis. As differences in reaction time between preferred and non-preferred hand are negligible (Benton and Joynt, 1958; Dimond, 1970), this could have no effects on the mean reaction time of subgroups. The panel was embedded in a tilted desk on which the subjects could rest their arms comfortably. Each test series consisted of 10 practice trials and 40 experimental trials. Each stimulus was preceded by a buzz as a warning signal, the foreperiod being one second. The interstimulus interval was five seconds. The total duration of the test was approximately 10 minutes. Although the effects of both practice and fatigue seem to be minimal in this time span (Benton and Blackburn, 1957; Costa, 1962; Bruhn and Parsons, 1971) and, if present, would work in opposite directions, we balanced the design for these time effects. In each subgroup, half of the patients started with the simple reaction while the other half started with the choice reaction.

Reaction time was recorded in hundredths of seconds on punch tape. Individual reaction times were calculated in milliseconds by taking the median over 40 trials. The median is a better index for the central tendency than the mean, as reaction time distributions tend to be skewed. 


\section{Results}

Figures 2 and 3 present the recovery curves for the simple and the choice reaction respectively. The data points for each test do not have exactly the same position on the time scale, as there were slight differences in the average interval after injury between subgroups. The shaded areas below indicate the normal range of a reference group of 45 healthy subjects, matched on age with the head injury group. Their upper and lower limits are based on the $90 \%$ and $10 \%$ lines in this normal group.

To test the overall effect of the independent variables, an ANOVA was carried out on the data, starting at the five months test (Table 2). Between subject factor was the severity of injury as indicated by length of coma (three levels).

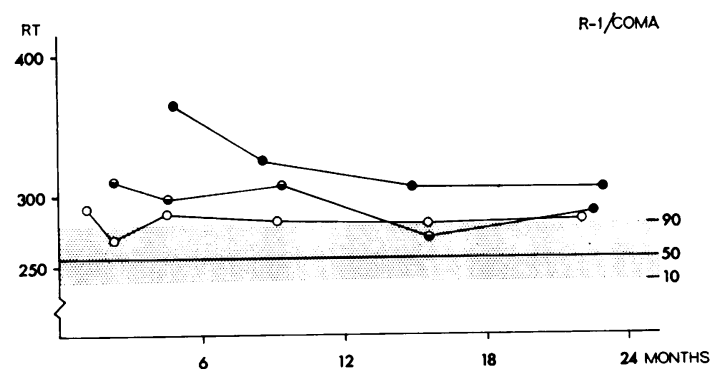

Fig. 2 Recovery curves for simple reaction time, as related to length of unconsciousness after injury. Shaded area below indicates the normal range of a noninjured reference group. On the abscissa number of months after injury is plotted. $\bullet=$ severely injured group, coma $3 ; \ominus=$ moderately injured group, coma 2 ; $\mathrm{O}=$ mildly injured group, coma 1.

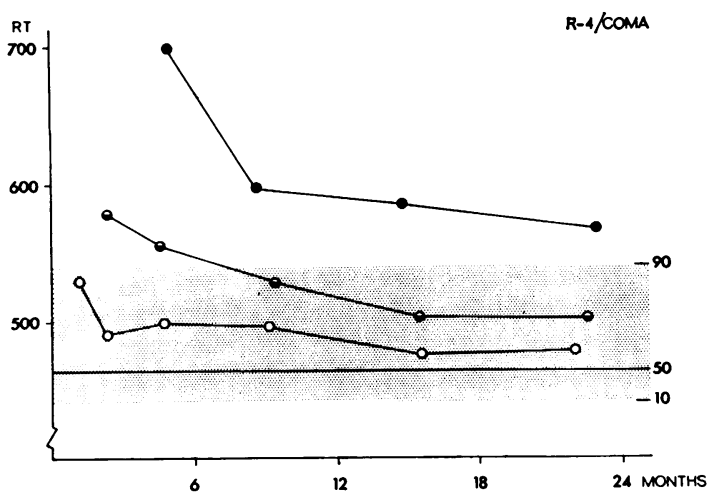

Fig. 3 Recovery curves for choice reaction time, as related to length of unconsciousness after injury. Symbols as in Fig 2.
Table 2 Analysis of variance with groups, complexity of task, and occasions as factors

\begin{tabular}{lrrr}
\hline Source & $d f$ & \multicolumn{1}{l}{$M S$} & \multicolumn{1}{l}{$F$} \\
\hline Between subjects & 34 & & \\
A & 2 & 135313.24 & $5.49^{*}$ \\
Ss within groups & 32 & 24657.29 & \\
Within subjects & 245 & & \\
B & 1 & 3584139.43 & $950.10^{*}$ \\
AB & 2 & 23652.34 & $6.27^{*}$ \\
B $\times$ Ss within groups & 32 & 3772.37 & $18.52^{*}$ \\
C & 3 & 24494.27 & $4.56^{*}$ \\
AC & 6 & 6029.76 & $8.61^{*}$ \\
BC Ss within groups & 96 & 1322.88 & 1.31 \\
ABC & 3 & 5624.34 & \\
BC $\times$ Ss within groups & 6 & 852.46 & \\
\hline
\end{tabular}

$\mathrm{A}=$ groups, $\mathrm{B}=$ complexity, $\mathrm{C}=$ occasions, $\mathrm{Ss}=$ subjects.

${ }^{*} \mathrm{P}<0.01$.

$X=$ multiple.

Within subject factors were complexity of task (two levels), and occasions of testing (four levels). Only the last four occasions were used because the severely injured group was not fit to be tested on earlier occasions. Although there were no defaulters in this study (all patients completed the two year follow-up), some subjects accidentally missed one of the tests. To keep the number of patients in each subgroup constant, we therefore had to restrict our analyses to those cooperative performers who never missed a single test in this period. The mean reaction times of the subgroups thus selected were virtually the same as those of the original patient groups. Furthermore, there was no relation between the missing of a single test and severity as indicated by duration of coma. As the number of subjects in each of the subgroups was roughly proportional to the respective probability of occurrence, a least squares solution for the effects and the sums of squares was chosen (Winer, 1970). The effect of groups was significant. The overall reaction times in each of the groups, ranked from mild to severe, were 386, 405 , and $465 \mathrm{~ms}$. The effect of complexity was highly significant (297 ms versus $524 \mathrm{~ms}$ ). The interaction of groups and complexity was also significant, the differences between simple and choice reaction being 198,228 , and $269 \mathrm{~ms}$ respectively in the mild, moderate, and severe group. There was also an effect of occasions, the mean values for overall reaction time being 435,414 , 395 , and $397 \mathrm{~ms}$.

The significant interaction between groups and occasions is a reflection of the different times at which each of the recovery curves approached the asymptote. The difference between the sixth and the third test was $8 \mathrm{~ms}$ for the mild group, $48 \mathrm{~ms}$ for the moderate group, and $79 \mathrm{~ms}$ for the severe 
group. Finally, there was an interaction of complexity and occasions: reaction time on the choice reaction task decreased until the sixth test, while the simple reaction time curve was almost flat already on the fourth occasion.

Table 3 Spearman correlations of reaction time performance at the five months test with clinical variables in the acute stage and with outcome after one year

\begin{tabular}{|c|c|c|}
\hline & $\begin{array}{l}\text { Simple } \\
\text { reaction } \\
\text { time }\end{array}$ & $\begin{array}{l}\text { Choice } \\
\text { reaction } \\
\text { time }\end{array}$ \\
\hline $\begin{array}{l}\text { Clinical variables } \\
\text { PTA duration } \\
\text { Coma duration } \\
\text { EMV score day six } \\
\text { EEG disturbances } \\
\text { EEG diffuse disturbance } \\
\text { EEG diffuse left } \\
\text { EEG local left par. temp. }\end{array}$ & $\begin{array}{l}.50 \\
.59^{*} \\
-.57^{*} \\
.21 \mathrm{NS} \\
.38 \\
.35 \\
.14 \mathrm{NS}\end{array}$ & $\begin{array}{c}.66^{*} \\
.62^{*} \\
-.69^{*} \\
.35 \\
.50 \\
.41 \\
.34\end{array}$ \\
\hline $\begin{array}{l}\text { Outcome } 12 \text { months } \\
\text { Clinical outcome } \\
\text { Mental scale } \\
\text { Memory deficits } \\
\text { Concentration deficit } \\
\text { Apathy/fatigue } \\
\text { Irritability } \\
\text { Social outcome }\end{array}$ & $\begin{array}{l}.55^{*} \\
.58^{*} \\
.51 \\
.50 \\
.49 \\
.19 \mathrm{NS} \\
.41\end{array}$ & $\begin{array}{l}.72^{*} \\
.60^{*} \\
.52^{*} \\
.46 \\
.58 * \\
.30 \\
.48\end{array}$ \\
\hline
\end{tabular}

NS = not significant; all other correlations significant at 0.05 or less, one-tailed test.

* = significant at 0.001 level.

PTA = post-traumatic amnesia, EEG = electroencephalogram, EMV = eye opening/motor/verbal score.

In Table 3 some Spearman correlations are given between reaction time performance at the five months test, clinical variables in the acute stage, and outcome at twelve months after trauma. All clinical variables and outcome were assessed by neurologists. Duration of post-traumatic amnesia and coma was rated on an eight point scale. All EEG variables were rated on time scales, correlating duration of disturbance with subsequent reaction time. Originally there were 17 EEG variables, including all possible local disturbances, epileptic activity, amplitude reduction, diffuse disturbances, and disturbed brain stem activity. Of these variables, only four resulted in significant correlations, diffuse disturbances over the left hemisphere being most likely to be associated with long reaction times.

Clinical outcome was rated on a seven point scale derived from that designed by Jennett and Bond (1975), ranging from good recovery without residual symptoms to a state of severe disability and dependence on others. The correlation coefficient of 0.72 seems to suggest that choice reaction time in particular has some predictive value in this range. The mental scale is composed of the scores on the next four variables (memory, concentration, apathy, irritability), all rated by the neurologist while interviewing the patient about his present state and complaints. Social outcome comprised items like work, family life, and leisure activities.

\section{Discussion}

The main effect of "groups" indicated that reaction time can discriminate between grades of severity in head injury patients. Further, the effect of "occasions" suggested that recovery is reflected in decreasing overall reaction times. The highly significant effect of "complexity" is hardly surprising as it has frequently been reported in normal subjects also (Fitts and Posner, 1973).

More interesting is the interaction between groups and complexity. There was an increasing difference between simple and choice reaction time with increasing severity. This suggests that choice reaction time is a more sensitive indicator of severity of injury as indicated by length of coma. Separate analysis of variance on each possible combination of subgroups shows that the interaction is caused mainly by the difference between the severely injured group and the other subgroups ( $P<0.01$ in both cases). In the comparison between the mild and moderate group, the interaction approached significance $(P=0.11)$. The disproportionate effect of the choice task on the severe group has been described as a complexity effect in an earlier report by the present authors (van Zomeren and Deelman, 1976). This effect was found in a comparison of head injury patients with normal subjects as well as in a comparison of patients with varying severity of injury. In terms of information theory, the complexity effect indicates that head injury influences channel capacity, or rate of information transmission in the central nervous system. It is interesting that information processing capacity seems to be reduced in proportion to the severity of the injury.

The second interaction, groups $\times$ occasions, was also significant. In other words, the slope of the recovery curve differed for the three subgroups. The mild group showed hardly any change, the severe group showed a considerable decrease in reaction time, while the moderate group took an intermediate position. The third interaction, complexity $\times$ occasions, showed that the slopes of recovery curves were different for simple and choice reaction times.

Visual inspection of Figs. 2 and 3 suggests that 
the power to discriminate between groups decreased faster for simple reaction time than for choice reaction time. This notion would have been supported by a significant three-way interaction of groups, complexity, and occasions. This interaction did not reach significance (Table 2). However, not all subjects were used in this analysis as it was restricted to those present for all four successive tests. In a final attempt to test the three-way interaction, the sizes of the respective groups were increased by taking into account the third and sixth tests only. All effects were in agreement with the original ANOVA, but they were even stronger this time. The three-way interaction was significant at the 0.05 level $\left(\mathrm{F}_{2 \cdot 44}=3.15\right)$. Separate analyses of variance showed that, as far as this second order interaction was concerned, the mild group differed significantly from the other groups $(\mathrm{P}<0.01$ in both cases). In both $\mathrm{RT}$ tasks this group was already approaching the asymptote at the third test. In the severe group both reaction times showed an improvement beyond the third test. In the moderate group, however, simple reaction time reached the level of the final performance already at the third test, while choice reaction time continued to improve. This longer lasting sensitivity is another argument in favour of choice reaction time. The conclusion that the choice reaction task is the best means for monitoring recovery seems justified. It is also a better predictor of final outcome, and correlates somewhat more highly with clinical variables and patients' complaints.

Figures 2 and 3 raise further questions. In the last test the mild and moderate groups showed normal choice reaction times, as compared with the baseline produced by noninjured controls. Their respective means were 500 and $478 \mathrm{~ms}$, normal choice reaction time being $479 \mathrm{~ms}$. The mean of the severe group was $568 \mathrm{~ms}$, which differed significantly from the normal score when tested with a one-tailed $t$ test $(P=0.0135)$. On the other hand, all three head injury groups remained significantly slow on the simple task. Their reaction times were 285, 290, and 309 ms respectively, normal reaction time being $265 \mathrm{~ms}$; with a one-tailed $t$ test the corresponding $\mathrm{P}$ values of differences were $0.001,0.005$, and 0.023 . It must be noted, however, that the data on normal subjects were the result of a single test. The following remarks may, therefore, be relevant. First, there might be a larger effect of learning on the choice reaction time, than on simple reaction time. In that case, it would not be fair to compare the patients' results on the sixth test with those of controls on their first and only occasion. Secondly, another possible explanation for the difference might be lessening motivation. When tested for the third or fourth time on the monotonous simple task, subjects might well lose their original zeal. Some evidence for this is found in the fact that the mildly injured group performed best in the second test (Fig. 2). On the other hand, choice reaction is far more challenging because of its unpredictable nature, and for that reason may keep the patients well-motivated.

In a slightly different theoretical framework, the prolonged simple reaction time may be interpreted as indicating a state of under arousal, even in the mildly and moderately injured subjects. As Gronwall and Sampson (1974) have suggested, the head injury patient may be in a state of chronic under arousal, due to dysfunction of his brainstem. Kahneman (1973) states that effort is mobilised in response to the changing demands of the tasks in which one engages. Under certain circumstances, a higher mental load may improve performance by raising the level of arousal. Therefore, it could be argued that the simple reaction fails to arouse the patients sufficiently, while the higher demands of the choice reaction result in an adequate level of arousal. This explanation does not conflict with the previous one, as high motivation in itself has an arousing value. It must be stressed, however, that the hypothesis of posttraumatic under arousal has so far not been tested directly by psychophysiological means.

A final remark can be made about late recovery in the severely injured group. Incidental retest of a few patients after more than two years suggested that there might be an improvement even in the third year after injury. We, therefore, decided to retest all patients in the severe group, but only 10 out of 12 could be traced. When retested at an average interval after trauma of 40 months, their mean choice reaction time had decreased from 581 to $556 \mathrm{~ms}$. This decrease was significant at the 0.10 level (one-tailed) only, when tested with a Wilcoxon Signed Ranks test (Conover, 1971). The change was due mainly to the slower half of the group, their mean reaction time having decreased from 655 to $613 \mathrm{~ms}$. This result must be regarded as suggesting the possibility of recovery beyond two years in the most severe cases. For that reason we feel that studies of recovery after severe head injury covering a period of more than two years might be interesting.

The authors are greatly indebted to Professor J. M. Minderhoud for supplying neurological information, and to J. S. Huizenga and W. H. Brouwer for their statistical advice. Finally, we 
would like to thank the head injury patients for their cooperation during the two years of the study.

\section{References}

Benton, A. L., and Blackburn. H. L. (1957). Practice effects in reaction time in brain-injured patients. Journal of Abnormal and Social Psychology, 54, 109-113.

Benton, A. L., and Joynt. R. J. (1958). Reaction time in unilateral cerebral disease. Confinia Neurologica, 19, 247-256.

Bruhn, P., and Parsons. O. A. (1971). Continuous reaction time in brain damage. Cortex, 7, 278-291.

Conover, W. J. (1971). Practical Nonparametric Statistics. John Wiley: New York.

Costa, L. D. (1962). Visual reaction time of patients with cerebral disease as a function of length and constancy of preparatory interval. Perceptual and Motor Skills, 14, 391-397.

Dimond, S. (1970). Reaction times and response competition between the right and left hands. Quarterly Journal of Experimental Psychology, 22, 513-520.

Fitts, P. M., and Posner, M. I. (1973). Human Performance. Prentice Hall International: London.

Gronwall, D. M. A., and Sampson, H. (1974). The Psychological Effects of Concussion. Auckland University Press: Auckland.
Gronwall, D. M. A., and Wrightson, P. (1974). Delayed recovery of intellectual function after minor head injury. Lancet, 2, 605-609.

Jennett, B., and Bond, M. R. (1975). Outcome after severe brain damage. A practical scale. Lancet, 1, 480-483.

Kahneman, D. (1973). Attention and Effort. Prentice Hall: Englewood Cliffs.

Klensch, H. (1973). Die diagnostische Valenz der Reaktionszeitmessung bei verschiedenen zerebralen Erkrankungen, Fortschritte der Neurologie und Psychiatrie, 41, 575-581.

Miller, E. (1970). Simple and choice reaction time following severe head injury. Cortex, 6, 121-127.

Norrman, B., and Svahn, K. (1961). A follow-up study of severe brain injuries. Acta Psychiatrica Scandinavica, 37, 236-264.

Russell, W. R., and Smith, R. (1961). PTA in closed head injury. Archives of Neurology (Chicago), 5, 4-17.

Teasdale, G., and Jennett, B. (1974). Assessment of coma and impaired consciousness. A practical scale. Lancet, 2, 81-84.

Van Zomeren, A. H.. and Deelman, B. G. (1976). Differential effects of simple and choice reaction after closed head injury. Clinical Neurology and Neurosurgery, 79, 81-90.

Winer, B. J. (1970). Statistical Principles in Experimental Design. McGraw Hill: London. 